medRxiv preprint doi: https://doi.org/10.1101/2022.01.17.22269403; this version posted January 18, 2022. The copyright holder for this preprint (which was not certified by peer review) is the author/funder, who has granted medRxiv a license to display the preprint in

All rights reserved. No reuse allowed without permission.

\title{
Assessing the contribution of gut-to-lung translocation to bacterial colonization and antibiotic resistance in an ICU patient
}

Rachel M Wheatley*1, Julio Diaz Caballero*1, Thomas E. van der Schalk ${ }^{2,8}$, Fien HR De Winter $^{3}$, Natalia Kapel ${ }^{1}$, Claudia Recanatini ${ }^{4}$, Leen Timbermont ${ }^{2}$, Jan Kluytmans ${ }^{4}$, Mark Esser $^{5}$, Alicia Lacoma ${ }^{6}$, Cristina Prat-Aymerich ${ }^{4,6}$, Antonio Oliver ${ }^{7,8}$, Samir Kumar-Singh ${ }^{2,3}$, Surbhi Malhotra-Kumar ${ }^{2,8}$, R. Craig MacLean ${ }^{1 * *}$ and WP3A working group.

These authors contributed equally *

Corresponding author** :craig.maclean@zoo.ox.ac.uk

${ }^{1}$ University of Oxford, Department of Zoology, 11a Mansfield Rd, Oxford

${ }^{2}$ Laboratory of Medical Microbiology, Vaccine and Infectious Disease Institute, Faculty of Medicine, University of Antwerp, Wilrijk, Belgium

${ }^{3}$ Molecular Pathology Group, Laboratory of Cell Biology and Histology, Faculty of Medicine, University of Antwerp, Wilrijk, Belgium

${ }^{4}$ Julius Center for Health Sciences and Primary Care, University Medical Center Utrecht, Utrecht University, Utrecht, The Netherlands

${ }^{5}$ Microbial Sciences, BioPharmaceuticals R\&D, AstraZeneca, Gaithersburg, MD, USA

${ }^{6}$ Microbiology Department, Hospital Universitari Germans Trias i Pujol, Institut d'Investigació Germans Trias i Pujol, CIBER Enfermedades Respiratorias, Universitat Autònoma de Barcelona, Badalona, Spain

${ }^{7}$ Servicio de Microbiología, Hospital Universitari Son Espases, Instituto de Investigación Sanitaria Illes Balears (IdISBa), Palma de Mallorca, Spain

${ }^{8}$ ESCMID study Group on Antimicrobial Surveillance (ESGARS)

WP3A working group

Christine Lammens ${ }^{2}$, Gert Leten², Anouk vanderStraeten², Omar Ali ${ }^{4}$ Alexey Ruzin ${ }^{4}$ 
medRxiv preprint doi: https://doi.org/10.1101/2022.01.17.22269403; this version posted January 18, 2022. The copyright holder for this preprint (which was not certified by peer review) is the author/funder, who has granted medRxiv a license to display the preprint in

All rights reserved. No reuse allowed without permission.

\begin{abstract}
:
Bacteria have the potential to migrate between sites in the human body, but the dynamics and consequences of within-host translocation remain poorly understood. Here we investigate the link between gut and lung Pseudomonas aeruginosa populations in an intensively sampled ICU patient using a combination of genomics, isolate phenotyping, host immunity profiling, and clinical data. Crucially, we show that lung colonization was driven by the repeated translocation of bacterial clones from the gut. Meropenem treatment for a suspected urinary tract infection selected for elevated resistance in both the gut and lung. However, resistance was driven by parallel evolution and organ-specific selective pressures, and within-host transmission had only a minor impact on AMR. These findings suggest that reducing intestinal colonization of Pseudomonas may be an effective way to prevent lung infections in critically ill patients.
\end{abstract}


medRxiv preprint doi: https://doi.org/10.1101/2022.01.17.22269403; this version posted January 18,2022 . The copyright holder for this preprint (which was not certified by peer review) is the author/funder, who has granted medRxiv a license to display the preprint in

All rights reserved. No reuse allowed without permission.

\section{Introduction:}

Bacteria often colonize multiple anatomical sites in human hosts, but the dynamics of withinhost translocation and its consequences for pathogenesis and host adaptation remain poorly understood $^{1-3}$. For example, advances in microbiome profiling methods have shown that the gut microbiome can transmit to the lungs of critically ill patients ${ }^{4,5}$, and translocation is associated with poorer outcomes in mechanically ventilated patients ${ }^{6}$. While gut-to-lung translocation has been demonstrated at the microbiome level, the dynamics and consequences of translocation for individual pathogens remain poorly understood.

$P$. aeruginosa is an opportunistic pathogen that is a major cause of healthcare-associated infections worldwide ${ }^{7,8}$, most notably in patients with compromised immunity ${ }^{9,10}$. Pseudomonas is not considered to be a typical member of the gut microbiome, and intestinal colonization with Pseudomonas is associated with an increased risk of developing lung infections $^{11-13}$ and mortality ${ }^{14}$. Gut colonization usually precedes lung infection, and the same strain is often found in the gut and lungs, suggesting that the gut acts as a reservoir of Pseudomonas that can be transmitted to the lung and other infection sites ${ }^{15-17}$. However, direct evidence for gut-to-lung transmission of $P$. aeruginosa is lacking, and it is possible that intestinal carriage simply reflects an innate susceptibility to Pseudomonas infection or proximity to a source of Pseudomonas that can independently colonize the lung and gut.

To test the importance of gut-to-lung transmission in Pseudomonas colonization and antimicrobial resistance (AMR), we carried out an in-depth case study on a single intensively sampled ICU patient over a 30-day period. We used phylogenetic approaches to test for transmission, and a combination of genomic and phenotypic methods to study the link between AMR and within-host transmission.

\section{Results:}

\section{Clinical timeline}

The focal patient was admitted to ICU of Hospital Universitari Germans Trias i Pujol in Badalona, Spain with a primary diagnosis of seizure. The patient was immediately treated with amoxicillin clavulanate, which is not active against $P$. aeruginosa, due to suspected aspiration of oropharyngeal or gastric contents into the lower respiratory tract. The patient was enrolled in ASPIRE-ICU trial ${ }^{18}$ at $48 \mathrm{hrs}$ post admission (hereafter day 1 ) and lung $P$. aeruginosa colonization was detected. Gut colonization was detected following meropenem treatment for a suspected urinary tract infection at day 12, and meropenem resistant $P$. aeruginosa ultimately colonized the lung. This complex clinical timeline suggests that translocation between the gut and lung may have occurred (Figure 1), but clinical data and isolate phenotypes alone provide limited insights into the underlying drivers of within-host transmission and AMR. 
medRxiv preprint doi: https://doi.org/10.1101/2022.01.17.22269403; this version posted January 18, 2022. The copyright holder for this preprint (which was not certified by peer review) is the author/funder, who has granted medRxiv a license to display the preprint in

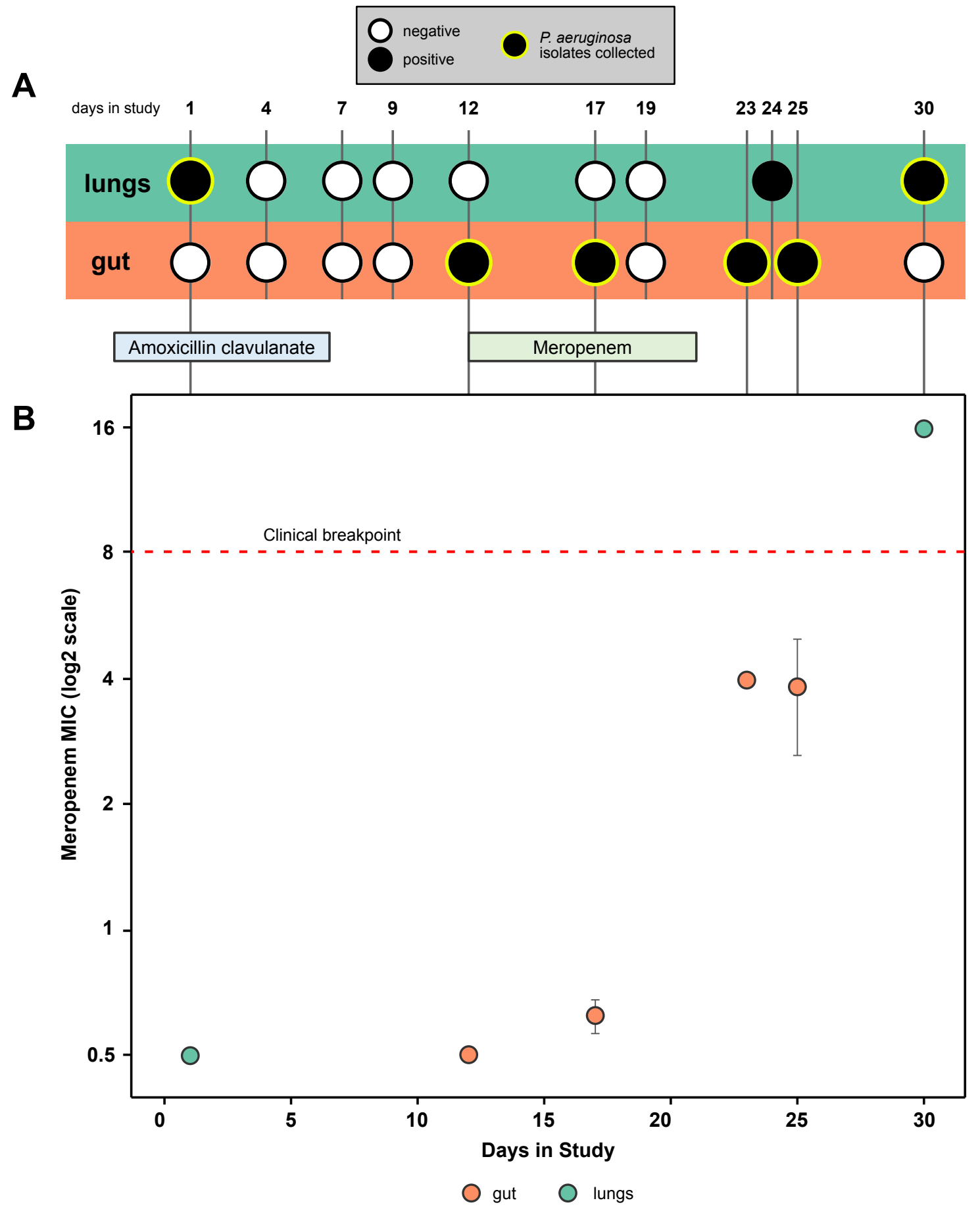

Figure 1: Clinical timeline and resistance phenotyping. (A) Timeline of patient sampling, showing samples that tested positive or negative for $P$. aeruginosa colonization. Sampling points from which isolates were collected are highlighted with a green ring. The patient was treated with Amoxicillin clavulanate from 2 days prior to enrolment until day 6 and with Meropenem from day 12 to day 21. (B) Meropenem minimum inhibitory concentration (MIC) (mean + /- standard error) for isolates from the gut (green) and lung (purple). Meropenem resistance increased over time, and $P$. aeruginosa isolates from the final lung sample were above the EUCAST clinical breakpoint for meropenem resistance (red dashed line). Amoxicillin clavulanate resistance was not measured as this antibiotic is not active against $P$. aeruginosa. 
medRxiv preprint doi: https://doi.org/10.1101/2022.01.17.22269403; this version posted January 18, 2022. The copyright holder for this preprint (which was not certified by peer review) is the author/funder, who has granted medRxiv a license to display the preprint in perpetuity.

All rights reserved. No reuse allowed without permission.

\section{Genomic insights into pathogen colonization and evolution}

To characterize the genetic diversity within this patient, we used long and short read sequencing to construct a hybrid assembly for a single isolate, yielding a $~ 6.3 \mathrm{Mb}$ ST782 reference genome distributed across 5 contigs. Short-read sequences of lung $(n=12)$ and gut $(n=40)$ isolates were mapped to this reference genome, and we identified polymorphic SNPs $(n=17)$, indels $(n=7)$, and variation in presence/absence of a $190 \mathrm{~kb}$ genomic island (Supplementary Table 1; Supplementary Figure 1).

The genetic diversity found in this patient could reflect either (i) recurrent colonization/infection by multiple clones or (ii) within-host evolution of a single clone. To discriminate between these processes, we reconstructed the phylogeny isolates using $P$. aeruginosa PA1, a closely related ST782 genome, as an outgroup (Figure 2A-D). The number of variants per isolate correlated strongly with the day of isolate collection (Figure $2 \mathrm{E} ; \mathrm{r}^{2}=.62$, $\mathrm{F}_{1,50}=82, \mathrm{P}<.0001$ ), supporting the idea that the within-patient diversity was driven by the evolution of a single cell that colonized the patient approximately 2 weeks prior to ICU admission while the patient was in the community (predicted MRCA at day $-15+/-3$ days). No other patients within the ASPIRE-ICU cohort at this hospital were colonized by $P$. aeruginosa ST782 during the trial, providing further support for the within-host diversification as opposed to repeated colonization. The rate of evolution in this patient was 51 SNPs/year (standard error (s.e.) $=5.84, \mathrm{t}=9.07, \mathrm{P}<.0001$ ), which is higher than the typical evolutionary rate of bacterial pathogens of 1-10 SNPs/year ${ }^{3}$. However, this elevated evolutionary rate is only $\approx 2$ fold greater than the rate reported from another patient in this trial ${ }^{19}$, highlighting the high in vivo mutation rate of $P$. aeruginosa in critically ill patients.

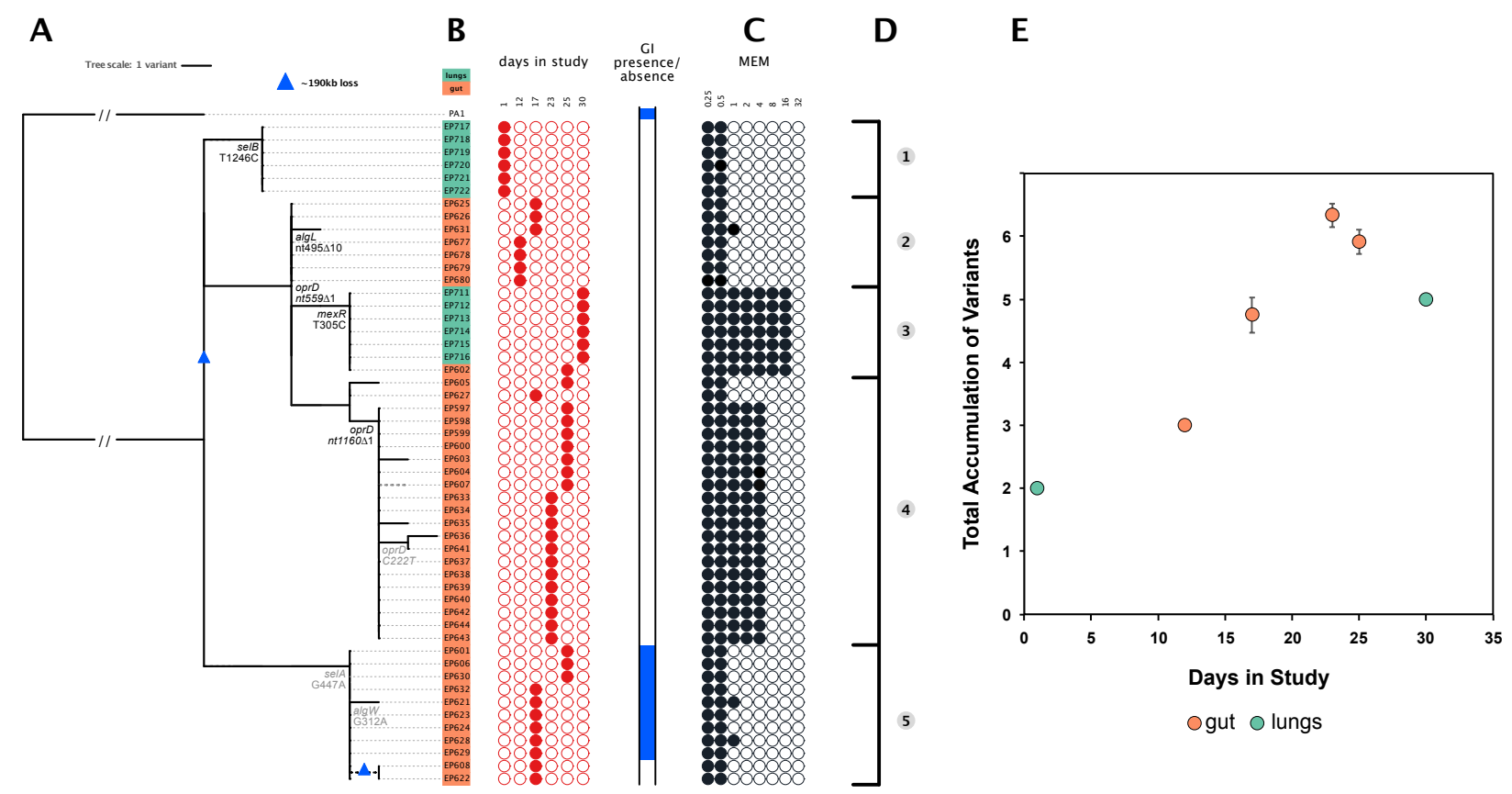

Figure 2: Genome sequencing and phylogenetic analysis $(A)$ Phylogenetic reconstruction of lung $(n=12)$ and gut $(n=40)$ isolates rooted using $P$. aeruginosa PA1, another ST782 isolate, as the outgroup. Putatively adaptive polymorphisms in genes or pathways showing parallel evolution are annotated on the phylogeny and silent mutations are shown in light grey. A polymorphism in a known multi-drug efflux pump regulator (mexR) is also highlighted. 
medRxiv preprint doi: https://doi.org/10.1101/2022.01.17.22269403; this version posted January 18, 2022. The copyright holder for this preprint (which was not certified by peer review) is the author/funder, who has granted medRxiv a license to display the preprint in perpetuity.

All rights reserved. No reuse allowed without permission.

Variation in the presence/absence of a $190 \mathrm{kB}$ genomic island is shown, and inferred losses of the genomic island are identified with blue triangles in the tree. (B) Isolate name, lung (green) or gut (orange) origin, and day in study of collection.n (C) Susceptibility to meropenem (MEM) for each isolate is presented with filled black circles in $\log _{2}$ scale of the minimum inhibitory concentration (MIC). (D) The topology of the tree suggested five distinct groups based on the identification of small polymorphisms. (E) Rate of accumulation of variants (mean +/- s.e) as a function of time per body site suggests within-host evolution of a clone rather than recurrent episodes of colonization.

Signatures of parallel evolution provide a simple way to identify putative beneficial mutations that underpin adaptation to the novel environment of the human host ${ }^{3,20}$. Parallel evolution occurred in 3 genes or operons that have functional roles in resistance to carbapenem antibiotics $(o p r D)^{20}$, alginate biosynthesis $(\operatorname{alg} W, a \lg L)^{21}$, and selenocysteine biosynthesis $(\text { sel } A \text { and selB })^{22}$. These putative pathoadaptive mutations accounted for 7 of the 24 variants, providing strong evidence for rapid adaptation to the host environment. Interestingly, 3 of these 7 mutations were synonymous, suggesting that transcription efficiency may have been a key target of selection ${ }^{23}$. The variable genomic island was lost on two independent occasions, suggesting that loss of this element was adaptive. Inferring the selective advantage of large scale deletions is difficult, but it is worth noting that this island carries pyoverdine biosynthesis genes that are selected against in the host environment ${ }^{24}$.

Bacterial phylogenies are a powerful tool to detect transmission events ${ }^{3,25,26}$. In this case, the most parsimonious explanation for the distribution of lung and gut isolates on the phylogeny is that Pseudomonas colonized the gut of the patient and then transmitted to the lung on at least two independent occasions (Figure 2). Initial lung colonization was driven by the gut to lung transmission of a lineage that acquired mutations in $g s / A$ and selB (Figure $2 A$ - lineage 1). The lack of diversity within this lineage suggests that this transmission event was driven by the outgrowth of a single cell soon before the patient was enrolled in the trial, possibly as a result of the broncoaspiration upon admission to ICU (i.e., at day -1). Secondary lung colonization (Figure $2 \mathrm{~A}$ - lineage 3 ) was caused by the growth of a clone with mutations in the oprD porin, which is a key carbapenem sensitivity determinant, and mexR, which regulates the expression the MexAB-OprM multi-drug efflux pump ${ }^{27}$ (Figure $2 \mathrm{~A}$ - lineage 2). This $o p r D / m e x R T 305 C$ lineage is nested within a broader clade of gut isolates, providing strong evidence that secondary lung colonization was driven by a second gut to lung transmission event likely occurred at some point after day 12 .

\section{Immune response to lung colonization}

Lung colonization provides $P$. aeruginosa with the opportunity to establish infection by adhering to the mucosal surface and penetrating the epithelial barrier, leading to the development of pneumonia. To investigate the role of host immunity in preventing infection, we measured the abundance of a panel of host immune effectors in samples of endotracheal aspirate (ETA) (Figure 3). Secondary lung colonization (day 17-19 samples) was associated with a host immune response that is indicative of a homeostatic and healing state, with high levels of expression of IL-33, Fractalkine, and IL-4, which have previously been to shown to enhance the clearance of $P$. aeruginosa ${ }^{28}$. Colonization was also associated with a $>10$-fold increase in the concentration of IL-22, which protects against infections caused by attaching and effacing bacterial pathogens by increasing mucous production and by limiting excessive 
medRxiv preprint doi: https://doi.org/10.1101/2022.01.17.22269403; this version posted January 18, 2022. The copyright holder for this preprint (which was not certified by peer review) is the author/funder, who has granted medRxiv a license to display the preprint in perpetuity.

All rights reserved. No reuse allowed without permission.

inflammation mediated by neutrophil influx ${ }^{29,30}$. Measuring cytokine levels in ETA samples from the lungs provides a direct measurement of immune response, but one concern over this approach is that it is possible for individual samples to give high concentrations of all cytokines, for example as a result of patient dehydration. However, in this case levels of IL-8 remained essentially constant across samples, supporting the idea spikes of protective cytokines were not an artefact.
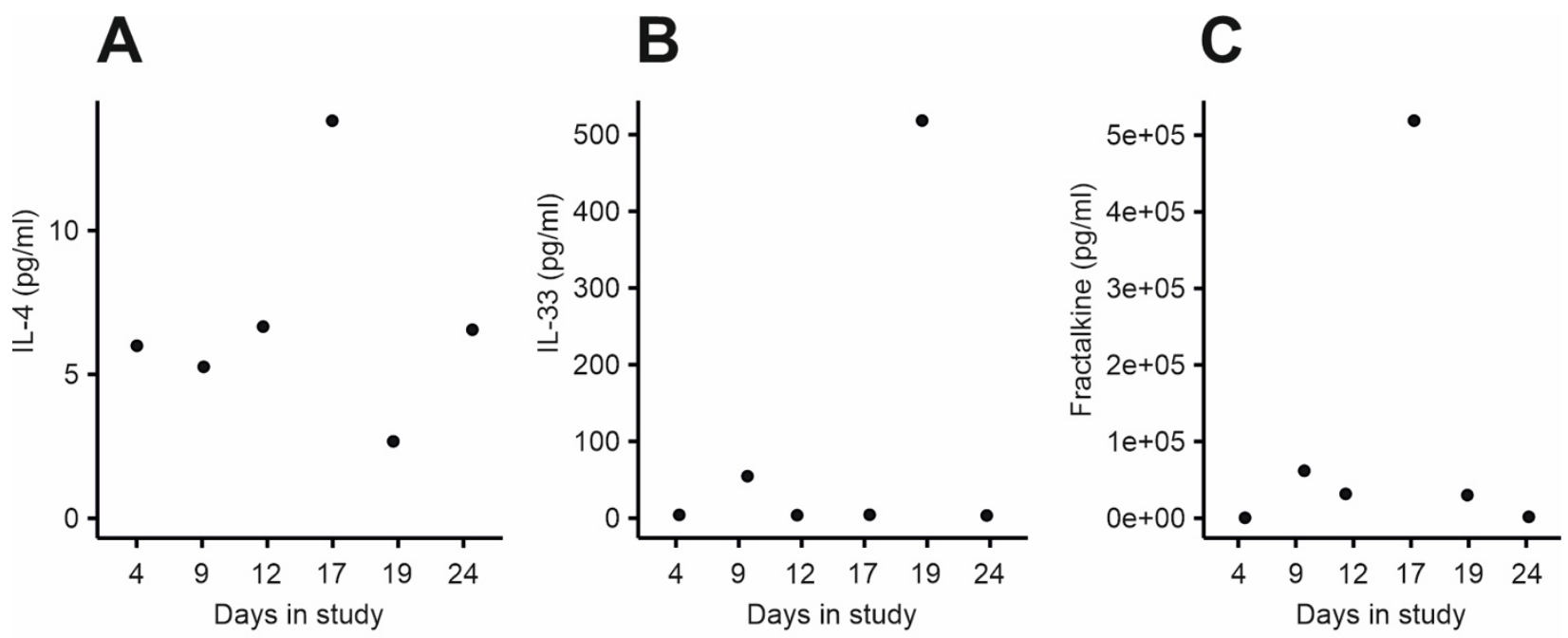

D
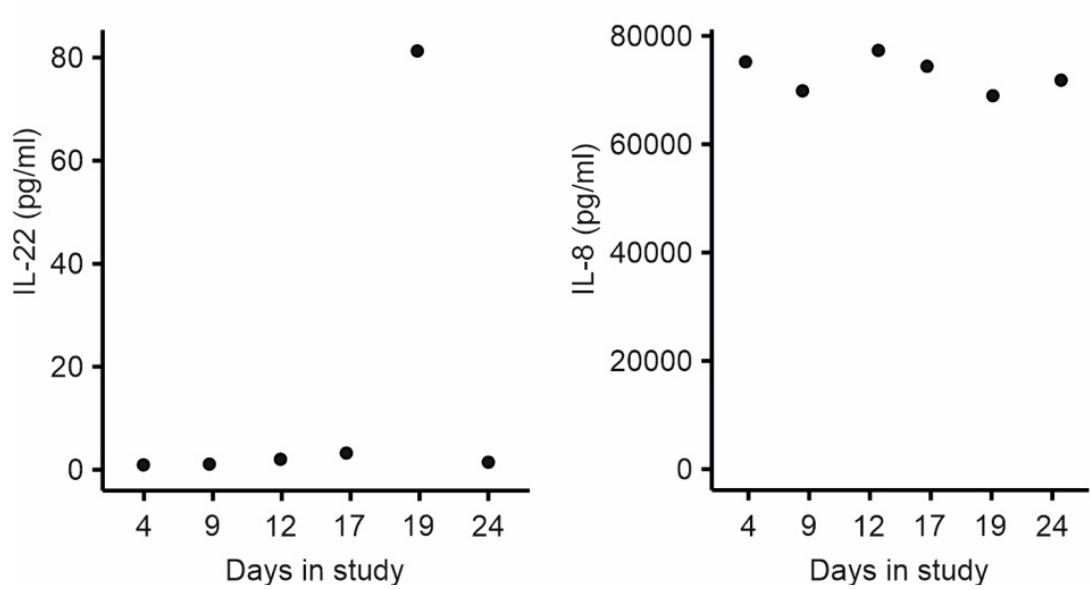

Figure 3: Cytokine concentrations were measured in ETA samples collected over the course of the study at days 4, 9, 12, 17, 19 and 24 . The following cytokines were measured: (A) IL-4, (B) IL-33, (C), Fractalkine, (D) IL-22, (E) IL-8.

\section{Drivers of antibiotic resistance}

$P$. aeruginosa has high levels of intrinsic antibiotic resistance and a remarkable ability to evolve increased resistance under antibiotic treatment ${ }^{31,32}$. Given the possibility of migration between the gut and lung, we next sought to understand the relative contributions of migration, mutation and selection to the origin and spread of meropenem resistance in this patient. The phylogeny clearly shows that elevated meropenem resistance evolved on 2 separate occasions due to mutations in oprD and $\operatorname{mex} R$ (Figure 2, lineages 4 and 5). However, it is challenging to follow the dynamics of meropenem resistance mutations using isolates alone due to the limited number of isolates sequenced $(n=52)$ and the gaps in the sampling of isolates. To overcome this problem, we combined isolate sequencing data with amplicon 
medRxiv preprint doi: https://doi.org/10.1101/2022.01.17.22269403; this version posted January 18, 2022. The copyright holder for this preprint (which was not certified by peer review) is the author/funder, who has granted medRxiv a license to display the preprint in perpetuity.

All rights reserved. No reuse allowed without permission.

sequencing of oprD using DNA extracted directly from ETA samples, some of which were not screened for isolates according to ASPIRE-ICU protocol (Figure 4A-B).
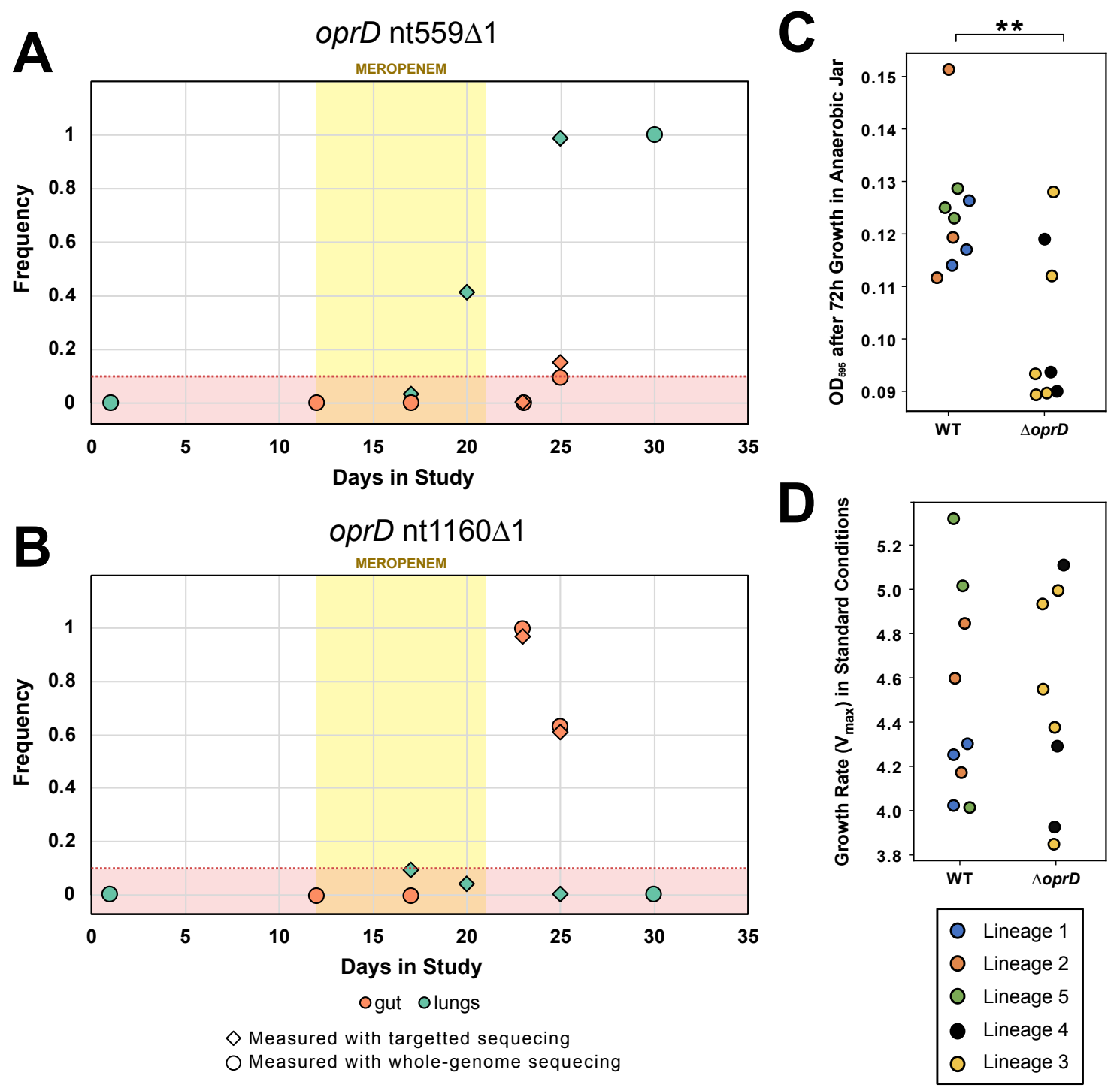

Figure 4: Evolution and transmission of meropenem resistance. ( $A$ and B) Dynamics of oprD variants, as determined by combining isolate WGS (circle) and oprD amplicon (diamond) sequencing data. The yellow area shows the window of meropenem treatment and the red area shows the minimum detection limit of variants from amplicon sequencing due to the high error rate of nanopore sequencing. The oprD nt559 1 variant was detected in a single gut isolate at day 25 (frequency=1/12) and the frequency of this variant in amplicons was marginally greater than the detection threshold (frequency $=97 / 671$ ). ( $C$ and $D$ ) Growth of isolates with an oprD variant $(\Delta$ oprD) compared to isolates with the wild-type oprD background. Anaerobic growth (C) was measured as $\mathrm{OD}_{595}$ after 72 hours growth in anaerobic broth. Aerobic growth (D) was measured as exponential growth rate in standard culture conditions. Isolates are colour coded according to phylogenetic lineage, as defined in Figure 2. oprD mutations were associated with impaired growth under anaerobic conditions $(P=.010)$, but not aerobic conditions $(P=.950)$, as judged by a nested ANOVA. Data from isolates from different lineages are shown together because fitness measures did not differ between lineages nested within oprD genotype $(P>.5)$. 
medRxiv preprint doi: https://doi.org/10.1101/2022.01.17.22269403; this version posted January 18, 2022. The copyright holder for this preprint (which was not certified by peer review) is the author/funder, who has granted medRxiv a license to display the preprint in perpetuity.

All rights reserved. No reuse allowed without permission.

The most common oprD mutation in sequenced isolates ( $\mathrm{nt1160 \Delta 1)}$ ) arose in the main clade of intestinal isolates (Figure 2, lineage 4) and it was never convincingly detected in lung samples (Figure 4B), providing good evidence that this mutation arose in the gut and swept to high frequency under meropenem treatment. Isolate sequencing revealed a second frameshift mutation in $\operatorname{opr} D(\mathrm{nt559 \Delta 1})$ that was linked to a mutation in the mexR effux pump transcriptional regulator. Isolate sequencing revealed the presence of the oprD $\mathrm{nt} 559 \Delta 1 /$ mexRT305C lineage in gut samples from day 25 and lung samples from day 30 , suggesting that that this lineage may have evolved resistance to meropenem in the gut and then transmitted to the lung. However, amplicon sequencing revealed that oprD nt559 1 swept to fixation in the lung during meropenem treatment (Figure $4 \mathrm{~A})$. This mutation was detected in gut isolates and amplicons that were sampled after meropenem treatment had ended (i.e. day 25), providing good evidence that the oprD nt559 1 mutation arose in the lung, and secondarily transmitted to the gut (Figure 4A).

Antibiotic concentrations vary between host tissues, and it is unclear to what extent pathogen populations adapt to local variation in selective pressures associated with antibiotic treatment. Meropenem achieves higher concentrations in lung tissues than in the gut ${ }^{33}$, suggesting that selection for resistance should be stronger in the lung than in the gut. Consistent with this expectation, isolates from the lung-associated oprD nt559 $\Delta 1 / \operatorname{mex} R T 305 \mathrm{C}$ lineage had higher meropenem resistance ( $M I C=16 \mathrm{mg} / \mathrm{L}$, s.e. $=0 \mathrm{mg} / \mathrm{L}, \mathrm{n}=19)$ than isolates from the gut-associated oprD nt1160 $\Delta 1$ lineage (MIC= $4 \mathrm{mg} / \mathrm{L}$, s.e. $=0 \mathrm{mg} / \mathrm{L}, \mathrm{n}=7$; Figure $2 \mathrm{C}$ ), demonstrating organ-specific adaptation to underlying differences in meropenem concentration.

A key challenge in evolutionary studies of $A M R$ is to understand how resistance can be maintained in pathogen populations in the absence of continued antibiotic use ${ }^{34,35}$. In this case, oprD nt559 1 resistance remained stable in the lung following antibiotic treatment, but the frequency of oprD nt1160 $\Delta 1$ declined in the gut due to the expansion of a carbapenem sensitive lineage (Figure $2 \mathrm{~A}$ - lineage 5 ). We speculate that this lineage may have survived carbapenem treatment by either colonizing a region of the gut with low carbapenem toxicity or by forming persister cells.

To test the role of selection in the stability of resistance, we measured the growth rate of isolates of all 5 major phylogenetic lineages in anaerobic culture medium (Figure 4C) and aerobic culture medium (Figure 4D), which recapitulates one of the physiological differences between the gut and lung. Meropenem resistant lineages ( $\triangle$ oprD) were not associated with decreased growth rate under aerobic conditions, suggesting that the oprD and mex $R$ mutations have little, if any, associated costs under these conditions (Figure 4D; $F_{1,12}=.0032$, $\mathrm{P}=.956)$. In contrast, both meropenem lineages were associated with decreased growth under anaerobic conditions, suggesting that fitness costs associated with oprD mutations drove the loss of resistance in the gut (Figure $4 \mathrm{C} ; \mathrm{F}_{1,12}=9.27, \mathrm{P}=.010$ ).

\section{Conclusion:}

The goal of this project was to understand the link between gut and lung Pseudomonas colonization in a single patient. By combining clinical and genomic data, we were able to demonstrate that transmission from the gut caused repeated lung colonization. Whilst it is 
medRxiv preprint doi: https://doi.org/10.1101/2022.01.17.22269403; this version posted January 18, 2022. The copyright holder for this preprint (which was not certified by peer review) is the author/funder, who has granted medRxiv a license to display the preprint in

All rights reserved. No reuse allowed without permission.

difficult to generalize the findings of a single case study, these findings support the idea that gut to lung transmission is a major driver of $P$. aeruginosa respiratory tract colonization in critically ill patients ${ }^{11,12,36}$. Lung colonization was associated with the production of cytokines that protect against $P$. aeruginosa infection, suggesting that a robust host immune response is key to preventing $P$. aeruginosa lung infection following lung colonization.

Carbapenem antibiotics such as meropenem are key to the treatment of $P$. aeruginosa infections ${ }^{19,37,38}$, and carbapenem-resistant $P$. aeruginos $a$ has been identified as an important threat by the World Health Organisation and the Centers for Disease Control and Prevention. In this patient, meropenem treatment for a suspected urinary tract infection drove the repeated evolution of resistance, providing a poignant example of the importance of 'bystander selection' for $\mathrm{AMR}^{39}$. Ultimately, selection led to the emergence of a stable population of highly resistant bacteria in the lung, suggesting that the respiratory tract can act as a source of carbapenem resistant Pseudomonas that can transmit to other body sites and potentially to other patients.

Migration increases genetic variation ${ }^{40}$, suggesting that within-host transmission may accelerate bacterial adaptation to antibiotics ${ }^{1-3,41-44}$. In this case resistance was driven by local mutation and selection within organs, leading to the emergence of a highly structured pathogen population ${ }^{1-3,43}$ shaped by a mosaic of selective pressures stemming from antibiotic treatment. We speculate that the high in vivo mutation rate of Pseudomonas was key to shaping local adaptation to antibiotic selection across tissues, and that within-host transmission is likely to provide a more important source of resistance at smaller spatial scales $^{2}$, or when mutation rate is low.

Hospital acquired infections caused by epidemically successful MDR and XDR strains of $P$. aeruginosa have become a serious problem worldwide ${ }^{45}$, and there is an urgent need to develop new antibiotics to treat infections caused by these strains. At the same time, the incredible ability of Pseudomonas to evolve resistance to antibiotic treatment ${ }^{19,31,32,41}$ highlights the need to develop novel approaches to prevent or treat Pseudomonas infections. Our study suggests that preventing gut colonization or gut to lung transmission may be an effective strategy for preventing Pseudomonas infection in critically ill patients ${ }^{46-49}$.

\section{Materials and methods:}

Clinical timeline

The patient was admitted to the intensive care unit (ICU) of Hospital Universitari Germans Trias i Pujol in Badalona, Spain with a primary diagnosis of seizure. At the time of ICU admission, the patient did not suffer from pneumonia or any other active $P$. aeruginosa infection (APACHE-II score $=22$ and Glasgow Coma scale $=3$ ). No antibiotic use was reported in the two weeks prior to hospital admission. After 48 hours of ICU admission, informed consent was obtained and the patient was enrolled in the ASPIRE-ICU study (day 1$)^{18}$. Mechanical ventilation (MV) was started on ICU admission and was continued for a total duration of 39 days. Amoxicillin/clavulanic acid (1000 mg IV q8h for 8 days) was started on ICU admission for bronchoaspiration, the suspected inhalation of oropharyngeal or gastric contents into the lower respiratory tract. Meropenem (1000 mg IV q8h for 10 days) was started on day 12 to treat a suspected urinary tract infection. Patient samples were collected 
medRxiv preprint doi: https://doi.org/10.1101/2022.01.17.22269403; this version posted January 18, 2022. The copyright holder for this preprint (which was not certified by peer review) is the author/funder, who has granted medRxiv a license to display the preprint in

All rights reserved. No reuse allowed without permission.

and screened for $P$. aeruginosa isolates as described in ${ }^{19}$ until day 30 , and the patient was discharged from the ICU and transferred to a general medical ward on day 41.

\section{Resistance phenotyping}

All isolates were grown from glycerol stocks on Luria-Bertani (LB) Miller Agar plates overnight at $37^{\circ} \mathrm{C}$. Single colonies were then inoculated into LB Miller broth for $18-20 \mathrm{~h}$ overnight growth at $37^{\circ} \mathrm{C}$ with shaking at $225 \mathrm{rpm}$. Overnight suspensions were serial diluted to $5 \times 10^{5}$ $\mathrm{CFU} / \mathrm{mL}$. Resistance phenotyping to meropenem was carried out as minimum inhibitory concentration (MIC) testing via broth microdilution as defined by EUCAST recommendations ${ }^{50,51}$, with the alteration of LB Miller broth for growth media and the use of $P$. aeruginosa PAO1 as a reference strain. Resistance to meropenem was assayed along a 2fold dilution series between $0.25 \mathrm{ug} / \mathrm{mL}-64 \mathrm{ug} / \mathrm{mL}$. We defined growth inhibition as $\mathrm{OD}_{595}<0.200$ and we calculated the MIC of each isolate as the median MIC score from three biologically independent assays of each isolate (Supplementary Table 2).

\section{Growth assays}

$P$. aeruginosa isolates were grown from glycerol stocks on LB Miller Agar plates overnight at $37^{\circ} \mathrm{C}$. Single colonies were then inoculated into LB Miller broth for 18-20 h overnight growth at $37^{\circ} \mathrm{C}$ with shaking at $225 \mathrm{rpm}$. Overnight suspensions were serially diluted to an $\mathrm{OD}_{595}$ of $\sim 0.05$ within the inner 60 wells of a 96-well plate equipped with a lid. To assess growth rate under standard aerobic conditions, isolates were then grown in LB Miller broth at $37^{\circ} \mathrm{C}$ and optical density (OD595nm) measurements were taken at 10-min intervals in a BioTek Synergy 2 microplate reader set to moderate continuous shaking. Growth rate (Vmax; $\mathrm{mOD} / \mathrm{min}$ ) was calculated as the maximum slope of OD versus time over an interval of ten consecutive readings, and we visually inspected plots to confirm that this captured log-phase growth rate. We measured the growth rate of all 52 gut and lung isolates with a minimum of seven biological replicates to assess the relationship between meropenem resistance and fitness (Supplementary Table 2). We measured anaerobic growth using an anaerobic jar (Thermo Scientific ${ }^{\mathrm{TM}}$ Oxoid $^{\mathrm{TM}}$ AnaeroJar ${ }^{\mathrm{TM}}$ base jar) system with anaerobic gas generating sachets (Thermo Scientific ${ }^{\mathrm{TM}}$ Oxoid $^{\mathrm{TM}}$ AnaeroGen ${ }^{\mathrm{TM}}$ sachets). An Oxoid Resazurin indicator strip was placed in the jar as an indicator to confirm generation of an anaerobic environment. For growth measurements, single colonies were inoculated into LB Miller broth in the wells of a 96-well plate and placed in the anaerobic jar for 72 hours, after which plates were removed and $\mathrm{OD}_{595}$ was measured. For the comparison of oprD variant $(\Delta$ oprD) isolates to wild-type oprD background (WT oprD) isolates, growth measurements were taken for a minimum of three isolates (and a minimum of three biological replicates) selected as representatives from each phylogeny group to generate a mean growth measurement for each $\Delta$ oprD and WT oprD group. To test for an association between oprD mutations and impaired growth we used a nested ANOVA that included main effects of oprD (ie either WT or $\Delta$ oprD, $1 \mathrm{df}$ ) and phylogenetic lineage nested within oprD (5 lineages shown in Figure 2, $3 \mathrm{df}$ ).

\section{Illumina sequencing}

All isolates were sequenced in the MiSeq or NextSeq illumina platforms yielding a sequencing coverage of $21 X-142 X$. Raw reads were quality controlled with the ILLUMINACLIP (2:30:10) and SLIDINGWINDOW $(4: 15)$ in trimmomatic v. $0.39^{52}$. Quality controlled reads were assembled for each isolate with SPAdes v. 3.13.1 $1^{53}$ with default parameters. These assemblies were further polished using pilon v. $1.23^{54}$ with minimum number of flank bases of 10 , gap 
medRxiv preprint doi: https://doi.org/10.1101/2022.01.17.22269403; this version posted January 18, 2022. The copyright holder for this preprint (which was not certified by peer review) is the author/funder, who has granted medRxiv a license to display the preprint in perpetuity.

All rights reserved. No reuse allowed without permission.

margin of 100,000 , and kmer size of 47 . Resulting contigs were annotated based on the $P$. aeruginosa strain UCBPP-PA14 ${ }^{55}$ in prokka v. 1.14.0 $0^{56}$. Each isolate was typed using the Pseudomonas aeruginosa multi-locus sequence typing (MLST) scheme from PubMLST (last accessed on 11.06.2021) ${ }^{57}$.

\section{Long-read sequencing}

Two isolates (EP717 and EP623) were sequenced using the Oxford nanopore MinION platform with a FLO-MIN106 flow-cell and SQK-LSK109 sequencing kit. EP717 had sequencing coverage of 141X and EP623 of 233X. Raw reads were basecalled using guppy v. $0.0 .0+7969 \mathrm{~d} 57$ and reads were demultiplexed using qcat v. 1.1 .0 (https://github.com/nanoporetech/qcat). Resulting sequencing reads were assembled using unicycler v. $0.4 .8^{58}$, which used SAMtools v. $1.9^{59}$, pilon v. $1.23^{54}$, and bowtie2 v. $2.3 .5 .1^{60}$, in hybrid mode with respective illumina reads. The EP717 assembly had a N50 of 1,797,327 for a total of 6,217,789 bases distributed in 11 contigs. The EP623 assembly had a N50 of 6,133,283 for a total of 6,330,243 bases distributed in 5 contigs.

\section{Variant calling}

To identify mutations and gene gain/loss during the infection, short-length sequencing reads from each isolate were mapped to each of the long-read de novo assemblies with BWA $v$. 0.7.17 ${ }^{61}$ using the BWA-MEM algorithm. Preliminary SNPs were identified with SAMtools and BCFtools v. 1.9. Low-quality SNPs were filtered out using a two-step SNP calling pipeline, which first identified potential SNPs using the following criteria: 1) Variant Phred quality score of 30 or higher, 2) At least 150 bases away from contig edge or indel, and 3) 20 or more sequencing reads covering the potential SNP position. In the second step, each preliminary SNP was reviewed for evidence of support for the reference or the variant base; at least $80 \%$ of reads of Phred quality score of 25 or higher were required to support the final call. An ambiguous call was defined as one with not enough support for the reference or the variant, and, in total, only one non-phylogenetically informative SNP position had ambiguous calls. Indels were identified by the overlap between the HaplotypeCaller of GATK v. 4.1.3.0 $0^{62}$ and breseq v. $0.34 .0^{63}$. The variable genome was surveyed using GenAPI v. $1.098^{64}$ based on the prokka annotation of the short-read de novo assemblies. The presence or absence of genes in the potential variable genome was reviewed by mapping the sequencing reads to the respective genes with BWA v.0.7.1761.

Patient sample DNA was derived from the ETA samples. Similar to the culture of these samples, samples were blended $(30,000 \mathrm{rpm}$, probe size $8 \mathrm{~mm}$, steps of $10 \mathrm{~s}$, max $60 \mathrm{~s}$ in total), diluted 1:1 v/v with Lysomucil (10\% Acetylcysteine solution) (Zambon SA, Belgium) and incubated for $30 \mathrm{~min}$ at $37{ }^{\circ} \mathrm{C}$ with $10 \mathrm{~s}$ vortexing every $15 \mathrm{~min}^{19}$. Thereafter, $250 \mu \mathrm{l}$ of the liquefied sample was used in the ZymoBIOMICS DNA Miniprep Kit (Zymo Research, CA USA) for DNA extraction.

\section{Amplicon Sequencing of oprD}

Amplicon sequencing of the oprD gene was carried out to quantify the presence of the two key oprD variants observed in the isolate sequencing in whole gDNA samples that were available from the lung and gut of this patient. Patient samples were blended $(30,000 \mathrm{rpm}$, probe size $8 \mathrm{~mm}$, steps of $10 \mathrm{~s}$, max $60 \mathrm{~s}$ in total), diluted $1: 1 \mathrm{v} / \mathrm{v}$ with Lysomucil (10\% Acetylcysteine solution) (Zambon SA, Belgium) and incubated for $30 \mathrm{~min}$ at $37^{\circ} \mathrm{C}$ with $10 \mathrm{~s}$ 
medRxiv preprint doi: https://doi.org/10.1101/2022.01.17.22269403; this version posted January 18, 2022. The copyright holder for this preprint (which was not certified by peer review) is the author/funder, who has granted medRxiv a license to display the preprint in

All rights reserved. No reuse allowed without permission.

vortexing every $15 \mathrm{~min}$, as described $\mathrm{in}^{19}$. Thereafter, $250 \mu \mathrm{l}$ of the liquefied sample was utilised in the ZymoBIOMICS DNA Miniprep Kit (Zymo Research, CA USA) for DNA extraction.

A PCR amplification strategy using barcoded primers to amplify the oprD gene $(1489 \mathrm{bp}$ product length) and add sample specific DNA barcodes was followed as described in ${ }^{65}$. The method used a universal reverse primer and sample specific forwards primers containing $12 \mathrm{nt}$ barcodes (Supplementary Table 3$)^{65}$. The barcoded oprD PCR products were pooled and sequenced on an Oxford nanopore MinION platform using a FLO-MIN106 flow-cell and the SQK-LSK109 Ligation Sequencing kit. Amplicon sequencing raw reads were basecalled using guppy v. $0.0 .0+7969 \mathrm{~d} 57$. This yielded 163,766 reads with an estimated read length N50 of $2.64 \mathrm{~kb}$. The data was demultiplexed allowing $2 / 12$ sequencing errors in the barcode sequence and a maximum of 1 error in the downstream and upstream 4-mer. To identify the genotype of each read, we searched for the 11-mer sequence including the variant base and 5 bases downstream and upstream from this position. Using this conservative approach, we recovered $32-43 \%$ of the reads (Supplementary Table 4).

\section{Cytokine measurements}

Levels of interleukin (IL-)4, IL-33, IL-22, IL-8 and fractalkine were measured in ETA as previously described ${ }^{19}$. Briefly, ETA was measured in a final dilution of $1 / 16$ on a U-plex panel (Mesoscale Discovery, Rockville, MD, USA) following the manufacturer's instructions. The plate was coated with capturing antibodies for $1 \mathrm{~h}$ with shaking incubation at room temperature followed by washing off the plate. Samples were loaded and incubated for $1 \mathrm{~h}$, after which the plate was washed and incubated with detection antibodies for $1 \mathrm{~h}$. A final wash was performed and MSD gold reading buffer was applied before reading the plate in the QuickPlex ${ }^{T M}$ SQ 120 (MSD).

\section{Supplementary Information:}

Supplementary Figure 1: Identification of genomic island. The mapping of Illumina and Oxford Nanopore sequencing data to the reference P. aeruginosa PA1 revealed isolates (e.g. EP608) that lacked a genomic region of $\sim 125 \mathrm{~kb}$. In addition, the depth of coverage of the 75 $\mathrm{kb}$ upstream region was $2 \mathrm{X}$ greater in isolates carrying the $\sim 125 \mathrm{~kb}$ region (e.g. EP623). This information revealed a $\sim 200 \mathrm{~kb}$ genomic region, which carried a second copy of the $\sim 75 \mathrm{~kb}$ region and additional $\sim 125 \mathrm{~kb}$ genetic content.

Supplementary Table 1: Genomic variants

Supplementary Table 2: Metadata for the $52 \mathrm{P}$. aeruginosa isolates collected in study, including meropenem MICs and growth measurements

Supplementary Table 3: Primer table

Supplementary Table 4: Reads recovered from amplicon sequencing experiments

\section{Acknowledgements:}

This research was supported by Wellcome Trust Grant (106918/Z/15/Z) and the Innovative Medicines Initiative Joint Undertaking under COMBACTE-MAGNET (Combatting Bacterial Resistance in Europe-Molecules against Gram-negative Infections, grant agreement no. 115737) and COMBACTE-NET (Combatting Bacterial Resistance in Europe-Networks, grant agreement no. 115523), resources of which are composed of financial contribution from the European Union's Seventh Framework Program (FP7/2007-2013) and EFPIA companies' in kind contribution. We thank the Oxford Genomics Center (funded by Wellcome Trust Grant 
medRxiv preprint doi: https://doi.org/10.1101/2022.01.17.22269403; this version posted January 18, 2022. The copyright holder for this preprint (which was not certified by peer review) is the author/funder, who has granted medRxiv a license to display the preprint in

All rights reserved. No reuse allowed without permission.

203141/Z/16/Z) for the generation and initial processing of Illumina sequence data. We thank the local ASPIRE ICU research team for their contribution to this project at Hospital Universitari Germans Trias i Pujol.

\section{Ethics statement}

The study protocol was approved by the Research Ethics Committee of the Germans Trias i Pujol University Hospital. This study was conducted according to the principles of the Declaration of Helsinki, in accordance with the Medical Research Involving Human Subjects Act and local guidelines in the participating countries.

\section{Competing interests}

The authors declare no competing interests.

\section{Literature Cited}

1 Jorth, P. et al. Regional Isolation Drives Bacterial Diversification within Cystic Fibrosis Lungs. Cell Host \& Microbe 18, 307-319 (2015).

2 Chung, H. et al. Global and local selection acting on the pathogen Stenotrophomonas maltophilia in the human lung. Nature communications 8, (2017).

3 Didelot, X., Walker, A. S., Peto, T. E., Crook, D. W. \& Wilson, D. J. Within-host evolution of bacterial pathogens. Nature Reviews Microbiology 14, 150-162 (2016).

4 Dickson, R. P. et al. Enrichment of the lung microbiome with gut bacteria in sepsis and the acute respiratory distress syndrome. Nature microbiology 1, 1-9 (2016).

5 Stanley, D. et al. Translocation and dissemination of commensal bacteria in poststroke infection. Nature medicine 22, 1277-1284 (2016).

6 Dickson, R. P. et al. Lung microbiota predict clinical outcomes in critically ill patients. American journal of respiratory and critical care medicine 201, 555-563 (2020).

$7 \quad$ Kang, C.-I. et al. Pseudomonas aeruginosa bacteremia: risk factors for mortality and influence of delayed receipt of effective antimicrobial therapy on clinical outcome. Clinical infectious diseases 37, 745-751 (2003).

8 De Bentzmann, S. \& Plésiat, P. The Pseudomonas aeruginosa opportunistic pathogen and human infections. Environmental microbiology 13, 1655-1665 (2011).

9 Fazeli, H. et al. Pseudomonas aeruginosa infections in patients, hospital means, and personnel's specimens. Journal of research in medical sciences: the official journal of Isfahan University of Medical Sciences 17, 332 (2012).

10 Yang, L. et al. Evolutionary dynamics of bacteria in a human host environment. Proceedings of the National Academy of Sciences 108, 7481-7486 (2011).

11 Bonten, M. J. M., Bergmans, D., Speijer, H. \& Stobberingh, E. E. Characteristics of polyclonal endemicity of Pseudomonas aeruginosa colonization in intensive care units - Implications for infection control. American Journal of Respiratory and Critical Care Medicine 160, 1212-1219 (1999).

12 Gomez-Zorrilla, S. et al. Prospective Observational Study of Prior Rectal Colonization Status as a Predictor for Subsequent Development of Pseudomonas aeruginosa Clinical Infections. Antimicrobial Agents and Chemotherapy 59, 5213-5219 (2015).

13 Fujitani, S., Sun, H. Y., Yu, V. L. \& Weingarten, J. A. Pneumonia due to Pseudomonas aeruginosa Part I: Epidemiology, Clinical Diagnosis, and Source. Chest 139, 909-919 (2011). 
medRxiv preprint doi: https://doi.org/10.1101/2022.01.17.22269403; this version posted January 18, 2022. The copyright holder for this preprint (which was not certified by peer review) is the author/funder, who has granted medRxiv a license to display the preprint in perpetuity.

All rights reserved. No reuse allowed without permission.

14 Marshall, J. C., Christou, N. V. \& Meakins, J. L. The gastrointestinal tract. The" undrained abscess" of multiple organ failure. Annals of surgery 218, 111 (1993).

15 Bertrand, X. et al. Endemicity, molecular diversity and colonisation routes of Pseudomonas aeruginosa in intensive care units. Intensive care medicine 27, 12631268 (2001).

16 Okuda, J. et al. Translocation of Pseudomonas aeruginosa from the intestinal tract is mediated by the binding of ExoS to an $\mathrm{Na}$, K-ATPase regulator, FXYD3. Infection and immunity 78, 4511-4522 (2010).

17 Markou, P. \& Apidianakis, Y. Pathogenesis of intestinal Pseudomonas aeruginosa infection in patients with cancer. Frontiers in cellular and infection microbiology 3, 115 (2014).

18 Paling, F. P. et al. Rationale and design of ASPIRE-ICU: a prospective cohort study on the incidence and predictors of Staphylococcus aureus and Pseudomonas aeruginosa pneumonia in the ICU. BMC Infectious Diseases 17, 643 (2017).

19 Wheatley, R. et al. Rapid evolution and host immunity drive the rise and fall of carbapenem resistance during an acute Pseudomonas aeruginosa infection. Nature Communications 12, 12 (2021).

20 Li, H., Luo, Y.-F., Williams, B. J., Blackwell, T. S. \& Xie, C.-M. Structure and function of OprD protein in Pseudomonas aeruginosa: from antibiotic resistance to novel therapies. International Journal of Medical Microbiology 302, 63-68 (2012).

21 Albrecht, M. T. \& Schiller, N. L. Alginate lyase (AlgL) activity is required for alginate biosynthesis in Pseudomonas aeruginosa. Journal of bacteriology 187, 3869-3872 (2005).

22 Gursinsky, T., Jäger, J., Andreesen, J. R. \& Söhling, B. A selDABC cluster for selenocysteine incorporation in Eubacterium acidaminophilum. Archives of microbiology 174, 200-212 (2000).

23 Lebeuf-Taylor, E., McCloskey, N., Bailey, S. F., Hinz, A. \& Kassen, R. The distribution of fitness effects among synonymous mutations in a gene under directional selection. Elife 8, (2019).

24 Andersen, S. B., Marvig, R. L., Molin, S., Johansen, H. K. \& Griffin, A. S. Long-term social dynamics drive loss of function in pathogenic bacteria. Proceedings of the National Academy of Sciences of the United States of America 112, 10756-10761, (2015).

25 De Maio, N., Wu, C.-H. \& Wilson, D. J. SCOTTI: Efficient Reconstruction of Transmission within Outbreaks with the Structured Coalescent. PLOS Computational Biology 12, e1005130, (2016).

26 Klinkenberg, D., Backer, J. A., Didelot, X., Colijn, C. \& Wallinga, J. Simultaneous inference of phylogenetic and transmission trees in infectious disease outbreaks. Plos Computational Biology 13, 32, (2017).

27 Adewoye, L., Sutherland, A., Srikumar, R. \& Poole, K. The mexR repressor of the mexAB-oprM multidrug efflux operon in Pseudomonas aeruginosa: characterization of mutations compromising activity. Journal of bacteriology 184, 4308-4312 (2002).

28 Jain-Vora, S. et al. Interleukin-4 enhances pulmonary clearance of Pseudomonas aeruginosa. Infection and Immunity 66, 4229-4236 (1998).

29 Aujla, S. J. et al. IL-22 mediates mucosal host defense against Gram-negative bacterial pneumonia. Nature Medicine 14, 275-281, doi:10.1038/nm1710 (2008).

30 Zheng, Y. et al. Interleukin-22 mediates early host defense against attaching and effacing bacterial pathogens. Nature Medicine 14, 282-289, (2008). 
medRxiv preprint doi: https://doi.org/10.1101/2022.01.17.22269403; this version posted January 18, 2022. The copyright holder for this preprint (which was not certified by peer review) is the author/funder, who has granted medRxiv a license to display the preprint in All rights reserved. No reuse allowed without permission.

31 Fish, D. N., Piscitelli, S. C. \& Danziger, L. H. Development of resistance during antimicrobial therapy - a review of antibiotic classes and patients characteristics in 173 studies. Pharmacotherapy 15, 279-291 (1995).

32 Breidenstein, E. B. M., de la Fuente-Nunez, C. \& Hancock, R. E. W. Pseudomonas aeruginosa: all roads lead to resistance. Trends in Microbiology 19, 419-426, doi:10.1016/j.tim.2011.04.005 (2011).

33 Nicolau, D. P. Pharmacokinetic and pharmacodynamic properties of meropenem. Clinical Infectious Diseases 47, S32-S40, (2008).

34 San Millan, A. S. et al. Positive selection and compensatory adaptation interact to stabilize non-transmissible plasmids. Nature Communications 5, 11, (2014).

35 Andersson, D. I. \& Hughes, D. Antibiotic resistance and its cost: is it possible to reverse resistance? Nature Reviews Microbiology 8, 260-271, (2010).

36 Gomez-Zorrilla, S. et al. Antibiotic Pressure Is a Major Risk Factor for Rectal Colonization by Multidrug-Resistant Pseudomonas aeruginosa in Critically III Patients. Antimicrobial Agents and Chemotherapy 58, 5863-5870, doi:10.1128/aac.03419-14 (2014).

37 Papp-Wallace, K. M., Endimiani, A., Taracila, M. A. \& Bonomo, R. A. Carbapenems: past, present, and future. Antimicrobial agents and chemotherapy 55, 4943-4960 (2011).

38 Yayan, J., Ghebremedhin, B. \& Rasche, K. Antibiotic resistance of Pseudomonas aeruginosa in pneumonia at a single university hospital center in Germany over a 10year period. PLoS One 10 (2015).

39 Tedijanto, C., Olesen, S. W., Grad, Y. H. \& Lipsitch, M. Estimating the proportion of bystander selection for antibiotic resistance among potentially pathogenic bacterial flora. Proceedings of the National Academy of Sciences of the United States of America 115, E11988-E11995, (2018).

40 Hartl, D. \& Clark, A. Principles of Population Genetics, 4th Edition. (Sinauer Associates, 2007).

41 Folkesson, A. et al. Adaptation of Pseudomonas aeruginosa to the cystic fibrosis airway: an evolutionary perspective. Nature Reviews Microbiology 10, 841-851, (2012).

42 Lieberman, T. D. et al. Parallel bacterial evolution within multiple patients identifies candidate pathogenicity genes. Nature Genetics 43, 1275-U1148, doi:10.1038/ng.997 (2011).

43 Young, B. C. et al. Severe infections emerge from commensal bacteria by adaptive evolution. elife 6, 25, doi:10.7554/eLife.30637 (2017).

44 Young, B. C. et al. Evolutionary dynamics of Staphylococcus aureus during progression from carriage to disease. Proceedings of the National Academy of Sciences of the United States of America 109, 4550-4555, (2012).

45 Horcajada, J. P. et al. Epidemiology and Treatment of Multidrug-Resistant and Extensively Drug-Resistant Pseudomonas aeruginosa Infections. Clinical Microbiology Reviews 32, (2019).

46 Liberati, A. et al. Antibiotic prophylaxis to reduce respiratory tract infections and mortality in adults receiving intensive care. Cochrane Database of Systematic Reviews (2000). 
medRxiv preprint doi: https://doi.org/10.1101/2022.01.17.22269403; this version posted January 18, 2022. The copyright holder for this preprint (which was not certified by peer review) is the author/funder, who has granted medRxiv a license to display the preprint in

All rights reserved. No reuse allowed without permission.

47 Wittekamp, B. H. et al. Decontamination strategies and bloodstream infections with antibiotic-resistant microorganisms in ventilated patients: a randomized clinical trial. Jama 320, 2087-2098 (2018).

48 De Smet, A. et al. Decontamination of the digestive tract and oropharynx in ICU patients. New England Journal of Medicine 360, 20-31 (2009).

49 Plantinga, N. L. et al. Selective digestive and oropharyngeal decontamination in medical and surgical ICU patients: individual patient data meta-analysis. Clinical Microbiology and Infection 24, 505-513 (2018).

50 http://www.eucast.org, The European Committee on Antimicrobial Susceptibility Testing. EUCAST Reading Guide for Broth Microdilution, Version 11.0 (2021).

51 http://www.eucast.org, The European Committee on Antimicrobial Susceptibility Testing. Breakpoint Tables for interpretation of MICs and Zone Diameters, Version 11.0 (2021).

52 Bolger, A. M., Lohse, M. \& Usadel, B. Trimmomatic: a flexible trimmer for Illumina sequence data. Bioinformatics 30, 2114-2120 (2014).

53 Bankevich, A. et al. SPAdes: a new genome assembly algorithm and its applications to single-cell sequencing. Journal of computational biology 19, 455-477 (2012).

54 Walker, B. J. et al. Pilon: an integrated tool for comprehensive microbial variant detection and genome assembly improvement. PLoS one 9, e112963 (2014).

$55 \mathrm{He}, \mathrm{J}$. et al. The broad host range pathogen Pseudomonas aeruginosa strain PA14 carries two pathogenicity islands harboring plant and animal virulence genes. Proceedings of the National Academy of Sciences 101, 2530-2535 (2004).

56 Seemann, T. Prokka: rapid prokaryotic genome annotation. Bioinformatics 30, 20682069 (2014).

57 Jolley, K. A., Bray, J. E. \& Maiden, M. C. Open-access bacterial population genomics: BIGSdb software, the PubMLST.org website and their applications. Wellcome open research 3 (2018).

58 Wick, R. R., Judd, L. M., Gorrie, C. L. \& Holt, K. E. Unicycler: resolving bacterial genome assemblies from short and long sequencing reads. PLOS computational biology 13, e1005595 (2017).

$59 \mathrm{Li}, \mathrm{H}$. et al. The sequence alignment/map format and SAMtools. Bioinformatics 25, 2078-2079 (2009).

60 Langmead, B. \& Salzberg, S. L. Fast gapped-read alignment with Bowtie 2. Nature methods 9, 357 (2012).

$61 \mathrm{Li}, \mathrm{H}$. \& Durbin, R. Fast and accurate short read alignment with Burrows-Wheeler transform. Bioinformatics 25, 1754-1760 (2009).

62 McKenna, A. et al. The Genome Analysis Toolkit: a MapReduce framework for analyzing next-generation DNA sequencing data. Genome research 20, 1297-1303 (2010).

63 Deatherage, D. E. \& Barrick, J. E. in Engineering and analyzing multicellular systems 165-188 (Springer, 2014).

64 Gabrielaite, M. \& Marvig, R. L. GenAPI: a tool for gene absence-presence identification in fragmented bacterial genome sequences. BioRxiv, 658476 (2019).

65 Ståhlberg, A. et al. Simple, multiplexed, PCR-based barcoding of DNA enables sensitive mutation detection in liquid biopsies using sequencing. Nucleic acids research 44, e105-e105 (2016). 